notion for the development of. validated PROM questionnaire for use following non-DCR, surgical intervention for epiphora.

\section{Compliance with ethical standards}

Conflict of interest The authors declare that they have no conflict of interest.

\section{References}

1. Sipkova Z, Vonica O, Olurin O, Obi EE, Pearson AR. Assessment of patient-reported outcome and quality of life improvement following surgery for epiphora. Eye. 2017;31:1664-71.

2. Munk PL, Lin DT, Morris DC. Epiphora: treatment by means of dacryocystoplasty with balloon dilatation of the nasolacrimal drainage apparatus. Radiology. 1990;177:687-90.

\title{
Exploring correlations between change in visual acuity following routine cataract surgery and improvement in quality of life assessed with the Glasgow Benefit Inventory
}

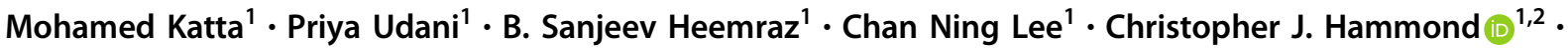 \\ Omar A. Mahroo $1,2,3,4$
}

Received: 15 January 2018 / Accepted: 25 April 2018 / Published online: 18 May 2018

(c) The Royal College of Ophthalmologists 2018

The Glasgow Benefit Inventory (GBI) [1] assesses patientperceived changes in quality of life following an intervention by means of 18 questions; the score ranges between a minimum of -100 (maximal detriment) to +100 (maximal benefit). As it is not procedure-specific, it can potentially be used to compare changes in quality of life following different interventions. Originally developed for use in otolaryngology, it has also been used in a range of oculoplastic procedures [2,3], and, more recently, we have deployed it after routine cataract surgery [4]. In the latter study, the questionnaire was administered to 109 patients, and significant improvement in quality of life was demonstrated with a positive GBI score.

Omar A. Mahroo

omar.mahroo@kcl.ac.uk

1 Department of Ophthalmology, St Thomas' Hospital, London SE1 7EH, UK

2 Department of Ophthalmology, King's College London, St Thomas' Hospital Campus, Westminster Bridge Rd, London SE1 7EH, UK

3 UCL Institute of Ophthalmology, University College London, 1143 Bath St, London EC1V 9EL, UK

4 Retinal Service, Moorfields Eye Hospital, 162 City Rd, London EC1V 2PD, UK
In the present study, we retrospectively retrieved visual acuity data for these patients (from the patient record) to explore correlation between change in visual acuity (decimalised) and GBI score. Patients for whom the preoperative or post-operative visual acuity was not available were excluded. 91 patients (83.5\%) were included: 48 were female; 53 were Caucasian, 30 Black, 3 Asian (5 had unrecorded ethnicity). The mean (SD) age was 71 (11) years.

Table 1 shows the main findings, and Fig. 1 plots GBI scores against change in visual acuity. For the whole cohort GBI score correlated positively with visual acuity with a Pearson correlation coefficient of $0.35\left(p=7 \times 10^{-4}\right)$. For first eyes, correlation was stronger than for second eyes. The visual acuity improvement for first eyes was greater than that for second eyes as might be expected (given the usual practice of operating on a worse seeing eye first). Importantly, an improvement in quality of life (positive GBI score) was seen after both first and second eye surgery, with no significant difference in scores, despite the difference in change in visual acuity. Mean pre and post-operative visual acuity did not differ significantly by ethnicity.

Our findings quantify the correlation between quality-of-life improvement, as measured by the GBI, and change in visual acuity. A significant correlation was seen. However, the strength of the correlation was 
Table 1 Change in visual acuity (VA) and Glasgow Benefit inventory (GBI) scores after first eye and second eye surgery

\begin{tabular}{|c|c|c|c|c|c|c|c|}
\hline & \multirow[t]{2}{*}{$n$} & \multicolumn{2}{|c|}{$\begin{array}{l}\text { Change in VA } \\
\text { (decimalised) }\end{array}$} & \multicolumn{2}{|l|}{ GBI score } & \multirow[t]{2}{*}{ Correlation coefficient } & \multirow[t]{2}{*}{ Significance $(p)$} \\
\hline & & Mean (SD) & $95 \% \mathrm{CI}$ & Mean (SD) & $95 \% \mathrm{CI}$ & & \\
\hline 1st eye & 57 & $0.44(0.37)$ & $0.34-0.54$ & $+23.6(18.2)$ & $18.8-28.5$ & 0.53 & $2 \times 10^{-5}$ \\
\hline 2nd eye & 34 & $0.22(0.32)$ & $0.11-0.33$ & $+22.4(23.4)$ & $14.2-30.6$ & 0.10 & 0.57 \\
\hline All patients & 91 & $0.36(0.37)$ & $0.28-0.44$ & $+23.2(20.2)$ & $19.0-27.4$ & 0.35 & $7 \times 10^{-4}$ \\
\hline
\end{tabular}

Pearson coefficients are given for correlation between change in VA and GBI score. 95\% CI, 95\% confidence interval for mean. The change in visual acuity was greater for first eyes compared with second eyes ( $p=0.005$, unpaired $t$ test), but GBI scores for first eyes and second eyes were similar $(p=0.68)$, indicating similar benefits in quality of life for first eyes and second eyes

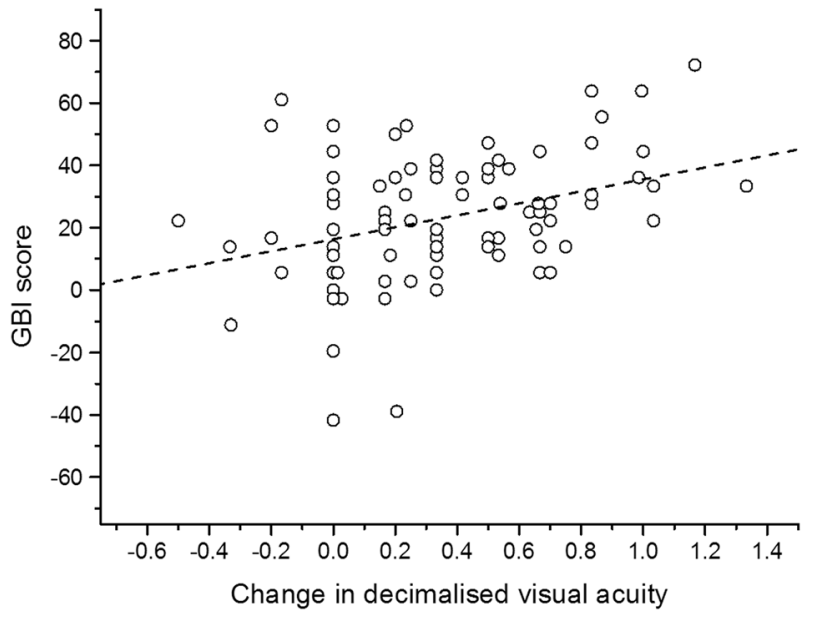

Fig. 1 GBI score plotted against change in decimalised visual acuity. The dashed line provides a simple linear fit. Correlation was found to be significant $\left(p=7 \times 10^{-4}\right)$

moderate to low overall, which supports the notion that change in visual acuity alone does not capture the full improvement in quality of life conferred by cataract surgery. This is especially true for second eyes. The improvement in visual acuity was less than that for first eyes, but the perceived improvement in quality of life appeared to be just as strong, suggesting that this is driven by factors other than visual acuity (possibly improved stereopsis or reduced anisometropia as well as other less quantifiable factors). Thus our findings confirm that the benefit of cataract surgery is not assessable by visual acuity alone, particularly in the case of second eyes.

Funding OAM receives support from the Wellcome Trust (Grant 206619_Z_17_Z), Fight for Sight, and the NIHR Biomedical Research Centre at Moorfields Eye Hospital and the UCL Institute of Ophthalmology.

\section{Compliance with ethical standards}

Conflict of interest The authors declare that they have no conflict of interest.

\section{References}

1. Robinson K, Gatehouse S, Browning GG. Measuring patient benefit from otorhinolaryngological surgery and therapy. Ann Otol Rhinol Laryngol. 1996;105:415-22.

2. Smith HB, Jyothi SB, Mahroo OA, Shams PN, Sira M, Dey S, et al. Patient-reported benefit from oculoplastic surgery. Eye. 2012;26: 1418-23.

3. Mahroo OA, Hysi PG, Dey S, Gavin EA, Hammond CJ, Jones CA. Outcomes of ptosis surgery assessed using a patient-reported outcome measure: an exploration of time effects. Br J Ophthalmol. 2013;98:387-90.

4. Heemraz BS, Lee CN, Hysi PG, Jones CA, Hammond CJ, Mahroo OA. Changes in quality of life shortly after routine cataract surgery. Can J Ophthalmol J Can d'ophtalmologie. 2016;51:282-7. 